\title{
A INFLUÊNCIA DO CURSO DE MATEMÁTICA BÁSICA DA ESCOLA POLITÉCNICA DA UNIVERSIDADE DE PERNAMBUCO EM SEUS MONITORES
}

Matheus de Amorim Barros - mab@poli.br

Escola Politécnica da Universidade de Pernambuco

Rua Benfica, 455

50.720-001 - Recife - Pernambuco

José Roberto de Souza Cavalcanti-jrcavalcanti@poli.br

Escola Politécnica da Universidade de Pernambuco

Rua Benfica, 455

50.720-001 - Recife - Pernambuco

João Carlos Batista de Oliveira - joaocbatista.contato@gmail.com

Escola Politécnica da Universidade de Pernambuco

Rua Benfica, 455

50.720-001 - Recife - Pernambuco

Matheus Henrique Torresda Silva-matheushtds@hotmail.com

Escola Politécnica da Universidade de Pernambuco

Rua Benfica, 455

50.720-001 - Recife - Pernambuco

Thiany Maria Correia Matias Ferreira - tmcmf@poli.br

Escola Politécnica da Universidade de Pernambuco

Rua Benfica, 455

50.720-001 - Recife - Pernambuco

Resumo: A Escola Politécnica de Pernambuco decidiu criar o Curso de Matemática Básica para os discentes ingressantes, tendo como finalidade realizar um nivelamento e, assim, prepará-los para suas novas realidades. Curso este, ministrado por discentes veteranos, com o pensamento de: quem melhor para esta preparação do que pessoas que já passaram pela mesma situação? Dando enfoque nestes monitores, este artigo tem por objetivo exibir uma pesquisa realizada com os mesmos, na qual é possível quantificar a influência no desenvolvimento ou aprimoramento de características pessoais e acadêmicas inerentes a docência e outras profissões. O estudo foi realizado utilizando a plataforma Google Forms, formada por um questionário dividido em duas etapas: a primeira consistindo em uma coleta de dados referentes ao perfil acadêmico, e, a segunda, abordando aspectos relevantes a formação de um perfil docente. O contato, obtido através de um banco de dados, realizou-se via e-mail e aplicativo de mensagens instantâneas, método mais eficaz de coleta. Como resultado, destaca-se: na primeira etapa, 10 dos 17 monitores concluintes da graduação ingressaram no Mestrado, continuando sua trajetória acadêmica. E, na segunda, 71,43\% dos entrevistados afirmaram a forte influência no desenvolvimento para elaboração de materiais didáticos e para a liderança de grupo ou turma, mostrando a influência que o projeto exerce 
sobre seu monitor. A partir disto, é possível confirmar o caráter formador e influenciador do projeto no desenvolvimento de tais atributos, e, com isto, a importância da pesquisa em mostrar o mérito do Curso para parte de seu corpo discente.

Palavras-chave: Docência. Influência. Matemática Básica. Monitor.

\section{INTRODUÇÃO}

A matemática tem a capacidade de trazer a possibilidade de soluções de problemas e modelagem de diferentes cenários, acarretando, assim, que no profissional engenheiro o seu uso extrapole os seus limites reguladores, visando trazer um vínculo com a realidade, e, ainda, almejando por experiências que tragam o estudante de engenharia a enfrentar problemas que necessitem de uma solução real (FERRUZI; ALMEIDA, 2013). A matemática também está presente nas matrizes curriculares dos cursos de engenharia e que, segundo Miranda e Laudares (2011) o seu uso - conforme competências e habilidades presentes nas diretrizes curriculares - faz-se substancial para a preparação do engenheiro em seus trabalhos com tecnologia, visão socioeconômica, entre outros aspectos.

Ferruzi e Almeida (2013) abordam também que a matemática é uma das principais causas da retenção e/ou desistência dos estudantes de engenharia. Dentre os motivos que acarretam nos índices de reprovação, além dos fundamentos de cálculo, temos as dificuldades intrínsecas do aluno, lacunas na sua base do conhecimento, e a dificuldade na diferença metodológica de Ensino Médio e Superior (NASCIMENTO, 2000 apud SANTOS, D. et al, 2012). Ainda, em um estudo feito por Almeida e Godoy (2016), dentre as causas da desistência do curso de engenharia, nas fontes pesquisadas pelos autores, e visando o âmbito pedagógico, $34 \%$ são devido às reprovações sucessivas de disciplinas do ciclo básico e $22 \%$ devido à deficiência na educação básica dos estudantes.

Ciente desses índices, em 2010 a Escola Politécnica da Universidade de Pernambuco POLI/UPE criou o Curso de Matemática Básica que busca auxiliar nas deficiências matemáticas apresentadas pelos alunos ingressantes de Engenharia e Física de Materiais. Além de nivelar os alunos para o que será encontrado por eles na disciplina de Cálculo Diferencial e Integral I, pois como mostra o estudo levantado por Freitas, Costa E. e Costa C. (2017) a tendência da evasão é ocorrer nos primeiros quatro semestres do curso, devido ao caráter das disciplinas do ciclo básico.

É importante, também, a ressalva de que a mudança das exigências para um indivíduo no âmbito profissional impactou na forma que a educação é passada, e como explica Coll (1994, p. 100, apud FERRUZI; ALMEIDA, 2013) trouxe uma visibilidade a métodos inadequados que baseiam-se na forma expositiva, onde o professor assume um papel de transmissor e o aluno de receptor dos conhecimentos. Álvares (2006) mostra, igualmente, que uma grande parcela de docentes que atuam no Ensino Superior não possuem formação pedagógica, e que considerável parte dos docentes engenheiros não levam em consideração teorias e discussões pedagógicas. A diferença metodológica entre níveis de Ensino (Médio e Superior) é um dos fatores para índices de retenção e evasão na graduação de engenharia, e visando esses aspectos, o Curso de Matemática Básica trás em seu diferencial a atuação de monitores que estão cursando sua graduação na POLI/UPE para ensinar nas turmas. Trazendo consigo uma nova perspectiva e dinâmica de aula, pois há pouco tempo eles estavam na mesma situação que esses alunos ingressantes.

Costa e Baltar $(2015$, p. 3) dizem que "o programa de monitoria tende a proporcionar ao monitor distintas possibilidades de aprimoramento do seu fazer docente, essencial em seu 
processo de formação". E que a própria monitoria está bastante linkada com a formação de professores, visto que em muitas escolas de engenharia o quadro docente é composto por exalunos monitores (SANTOS; BOSCAINO; PAVÃO, 2006).

Dessa maneira, para o estudo proposto neste artigo, procurou-se identificar quais as influências e impactos do Curso de Matemática Básica em seu aluno-monitor, buscando saber o quão isso repercutiu em sua decisão de carreira profissional. Tal qual o efeito em comportamentos pessoais/acadêmicos, e demais aspectos pertinentes ao exercício da monitoria neste curso em específico.

\section{METODOLOGIA}

Por ser um Curso com longo período de existência, o mesmo tem um número significativo de monitores, 64. Por isso, a melhor maneira de contatar todos, já que alguns já se formaram, seria por meio de um formulário online. Com esse pensamento, a Coordenação do Curso, integrada por discentes e docentes, utilizou a plataforma 'Google Forms' para criar o formulário e realizar o recolhimento de dados. A partir disso, ao fazer uso do banco de dados existente, onde localiza-se os contatos dos monitores, foi realizada a divulgação por meio de e-mails e das mídias sociais. No formulário continham 16 perguntas, em sua maioria de múltipla-escolha, que foram divididas em duas etapas. Na primeira etapa, o monitor preenche dados acadêmicos, enquanto que na segunda, são colhidos dados referentes à influência do Curso de Matemática Básica no desenvolvimento ou no aprimoramento de algumas características do monitor.

A primeira etapa foi constituída por 10 questões, sendo os dois primeiros itens de âmbito pessoal - nome completo e endereço de e-mail - e os demais itens de caráter acadêmico curso de graduação, período em que foi monitor do Curso, ano de ingresso na POLI/UPE, se já concluiu o curso, quantos semestres levou para concluir, participação em outros Projetos na POLI/UPE ou estágio, bem como também, o que foi feito após finalizar a graduação (pósgraduação, mestrado, inserção direta no mercado de trabalho, dentre outras opções) - com o intuito de criar um perfil acadêmico para os monitores do Projeto.

$\mathrm{Na}$ segunda etapa, pretendeu-se, ao fazer a coleta dos dados, avaliar a relação de sua experiência como monitor do Matemática Básica e o impacto da participação neste Projeto para: desenvolvimentos e/ou aperfeiçoamentos pessoais - essenciais para uma possível prática docente -, contribuição para a graduação de cada monitor, bem como no seu futuro interesse na área de Docência. Com essa ideologia, foram utilizadas 6 questões, nesta etapa, de forma que pudesse quantificar a contribuição do Curso nos contextos supracitados, numa escala de 0 a 10, as seguintes questões apresentadas no Quadro 1:

Quadro 1 - Perguntas presentes na segunda etapa do questionário.

1. Para sua oratória?

2. Para sua organização didática?

3. Para liderança de turma/grupo?

4. Para elaboração de materiais didáticos (aulas, pesquisas, etc)?

5. Para seu aprendizado nas disciplinas no curso com alto grau de matematicidade?

6. Na graduação do seu curso na POLI/UPE?

Fonte: Autor (2020) 
Com base nas respostas obtidas através do formulário, foi possível quantificar a influência do Curso para a conclusão da graduação, bem como para o desenvolvimento de características que pudessem levar ao monitor o interesse a docência.

\section{RESULTADOS}

Ao longo desta pesquisa foi possível recolher 42 respostas, de um total de 64 monitores que já participaram e ainda participam do Curso, ou seja, 65,62\%. Com os resultados do questionário em posse pôde-se notar que: 33,33\% eram graduandos de Engenharia Civil; 21,4\% de Engenharia Elétrica - Eletrotécnica; 11,9\% de Engenharia Elétrica Telecomunicações; 9,5\% de Engenharia Mecânica Industrial; 9,5\% de Engenharia de Controle e Automação; 7,1\% de Engenharia Elétrica - Eletrônica; 7,1\% de Engenharia da Computação. Além disso, observou-se que 40,48\%, ou seja, 17 entrevistados, já concluíram a graduação, enquanto que 59,52\% ainda não. A partir disso, uma análise das perguntas mais relacionadas às áreas de atuação desses discentes tanto durante como depois de suas graduações, que estão presentes na primeira etapa, será feita. Assim como também, das perguntas da segunda etapa.

\subsection{Etapa 1}

Em algumas questões dessa etapa, procurou-se saber sobre as atividades extracurriculares nas quais os monitores estavam - ou estão - envolvidos. Assim como também, para os que já concluíram a graduação, se permaneceram na área acadêmica (mestrado, doutorado, dentre outros;) ou se já estão no mercado de trabalho, atuando em áreas relacionadas com sua graduação. Formando, assim, o perfil acadêmico dos monitores do Curso. Para todos os itens abordados nesta etapa, foi possível marcar mais de uma resposta, justificando a maior quantidade de respostas em relação a quantidade de entrevistados.

$\mathrm{Na}$ Figura 1, pode-se observar as atividades extracurriculares em que os monitores estavam envolvidos, tanto os que ainda estão na POLI/UPE, como os que já se formaram:

Figura 1 - Resultados referentes à área de atuação dos monitores durante a graduação.

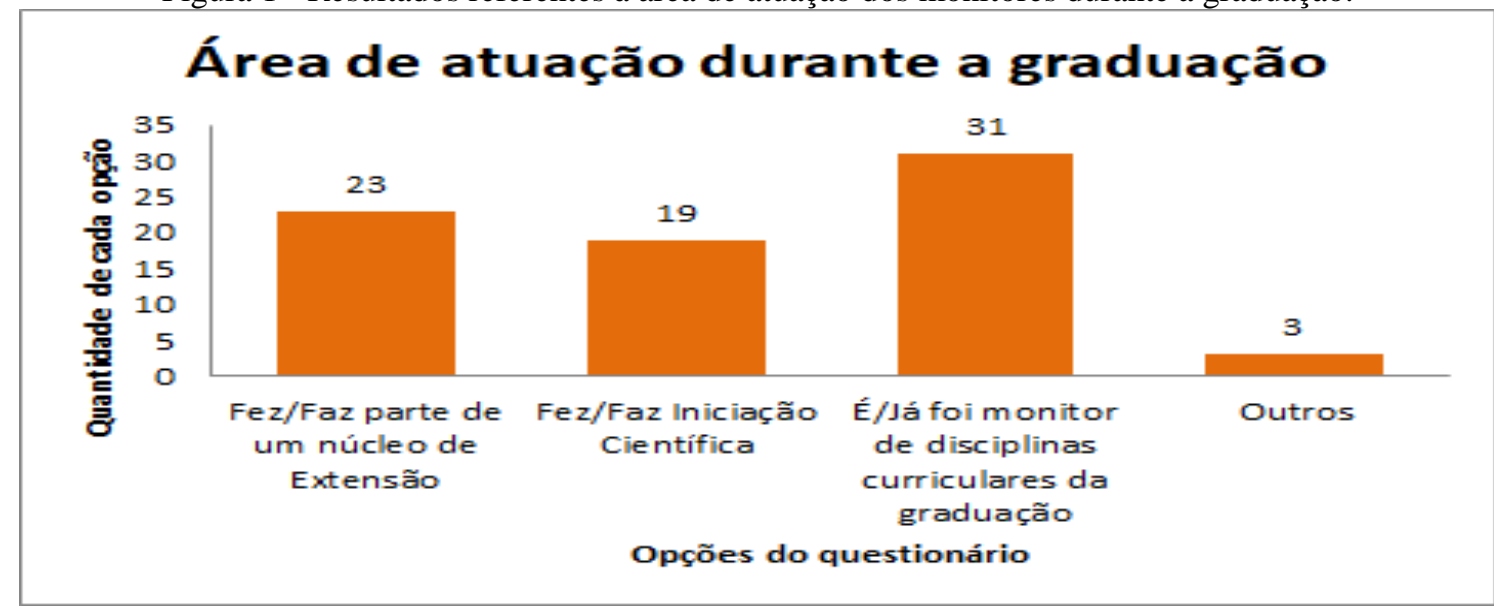

Fonte: Autor (2020).

Estes resultados, apresentados na Figura 1, apontam que: 40,79\% afirmaram que são ou já foram monitores de disciplinas presentes na grade curricular; 30,26\% afirmaram que fazem ou fizeram parte de um núcleo de Extensão; 25,00\% afirmaram que fazem ou fizeram Iniciação Científica; 3,95\% afirmaram que fazem ou fizeram parte de outros projetos da POLI/UPE. O que mostra que, boa parte dos monitores, mesmo que uma única pessoa 
C COBENCE 2020

"Os desafios para formar hoje o engenheiro do amanhã"
$\mathrm{Ol}$ a $\mathrm{O} 3$ de dezembro Evento On-line

pudesse marcar mais de uma alternativa, se aprofundou na parte acadêmica e usufruiu dos projetos existentes na Universidade. Desta forma, ganhando experiência na sua área de atuação.

Na Figura 2, é possível visualizar, para os que já se formaram, a quantidade que optou por seguir na área acadêmica:

Figura 2 - Resultados referentes à destinação acadêmica dos monitores já graduados.

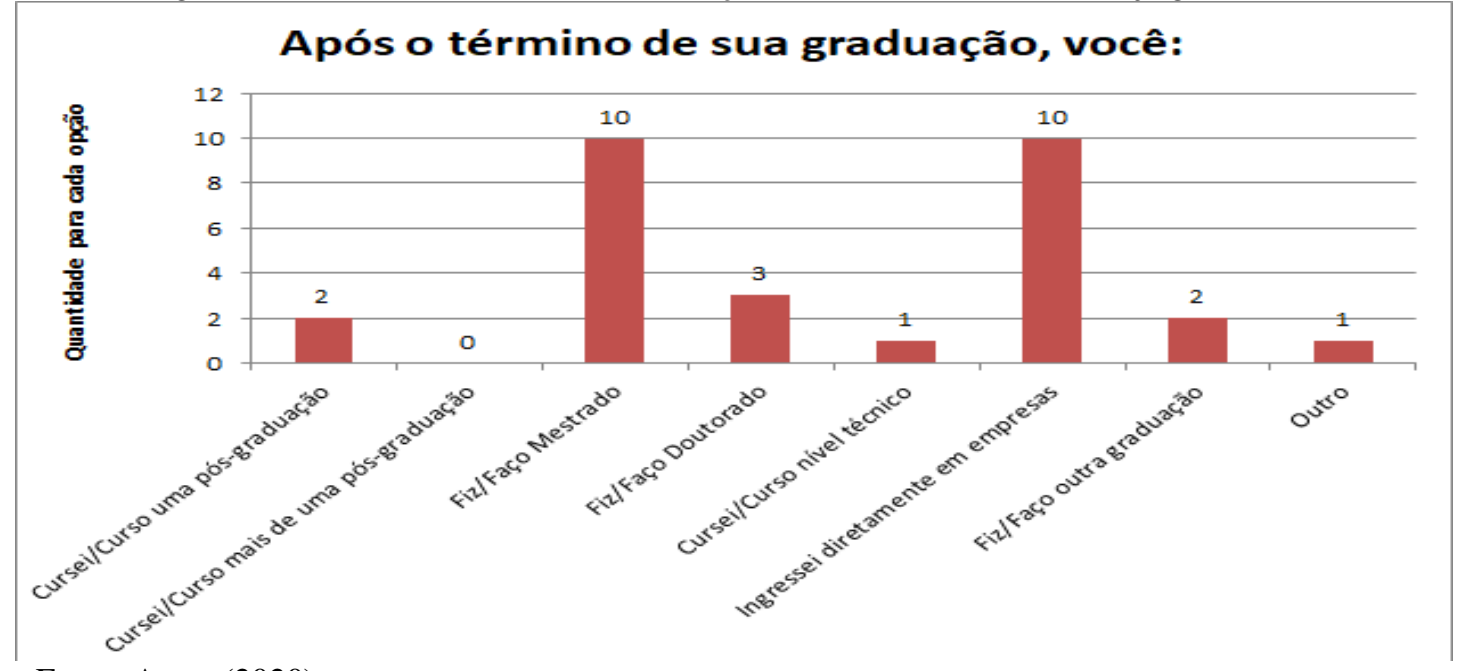

Fonte: Autor (2020).

Os resultados adquiridos, mostrados na Figura 2, indicam que: 34,48\% afirmaram que fazem ou fizeram mestrado; $34,48 \%$ afirmaram que ingressaram diretamente em empresas; $10,34 \%$ afirmaram que fazem ou fizeram doutorado; $6,90 \%$ afirmaram que fazem ou fizeram outra graduação; 6,90\% afirmaram que estão cursando ou cursaram uma pós-graduação; $3,45 \%$ afirmaram que cursam ou cursaram técnico; $3,45 \%$ afirmaram que fazem ou fizeram outra atividade acadêmica; $0,00 \%$ afirmou que cursou mais de uma pós-graduação. Observando por esta perspectiva, é notável que eles buscaram estender seu currículo acadêmico e se aprofundaram de fato na área de pesquisa, o que pode levar a uma eventual carreira docente. Bem como também, em contrapartida, uma outra parte já está atuando no mercado de trabalho.

Na Figura 3, mostra os resultados referentes à área de atuação dos monitores depois da graduação:

Figura 3 - Resultados referentes à área de atuação dos monitores depois da graduação.

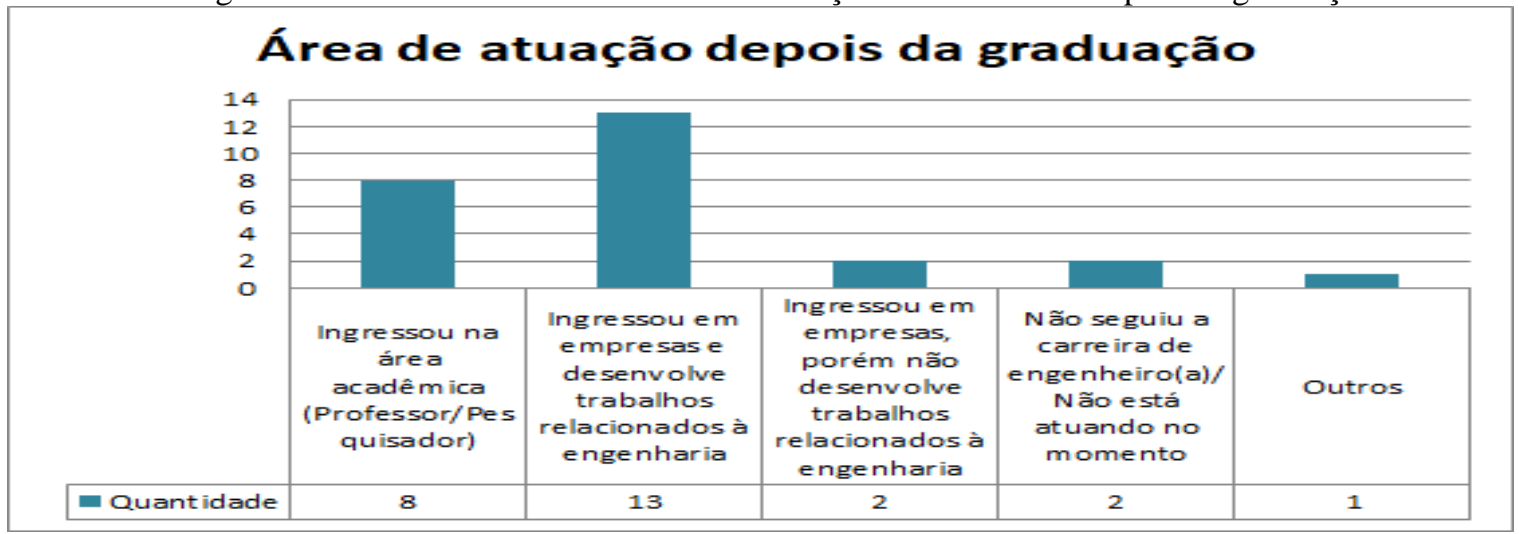

Fonte: Autor (2020). 
Os resultados expostos, na Figura 3, expressam que: 50,00\% afirmaram que ingressaram em empresas e desenvolvem trabalhos relacionados à Engenharia; 30,77\% afirmaram que ingressaram na área acadêmica, tanto como professor, quanto como pesquisador; 7,70\% afirmaram que ingressaram em empresas, mas não desenvolvem trabalhos relacionados à Engenharia; 7,70\% afirmaram que não seguiram carreira de Engenheiro(a) ou não estão atuando no momento; 3,83\% afirmaram que estão atuando em outras áreas. Nota-se assim, que a grande maioria já ingressou no mercado de trabalho, seja como docente ou em empresas, onde, felizmente, a porcentagem maior é dos que trabalham na área de sua graduação.

\subsection{Etapa 2}

Nesta etapa, as opções de escolha eram feitas numa escala de 0 a 10 , como já dito anteriormente. Com os resultados já obtidos, a coordenação optou por criar um nivelamento com base nestas respostas, de maneira que pudesse analisar melhor - sem tantas variantes - a influência exercida pelo Curso em características que auxiliam, tanto no desenvolvimento do exercício da docência, quanto no desenvolvimento pessoal. Dessa forma, foi feita a seguinte equiparação: de 0 a 2 corresponde a "não influenciou"; de 3 a 5 "influenciou pouco"; de 6 a 8 "influenciou"; 9 a 10 "influenciou muito".

Nas figuras a seguir - Figura 4, Figura 5 e Figura 6, respectivamente -, é possível visualizar os resultados obtidos sobre o quanto o curso influenciou no desenvolvimento ou aprimoramento de características essenciais para a prática Docente:

Figura 4 - Resultados referentes à influência do Curso para oratória dos monitores.

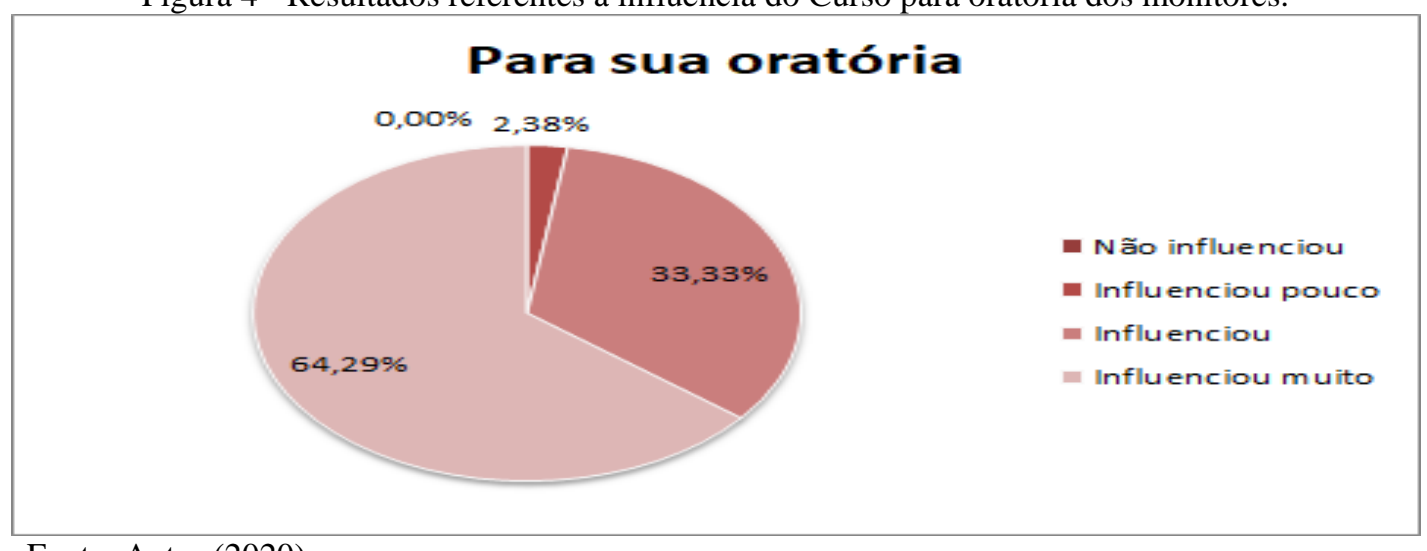

Fonte: Autor (2020).

Figura 5 - Resultados referentes à influência do Curso para organização didática dos monitores.

Organização didática

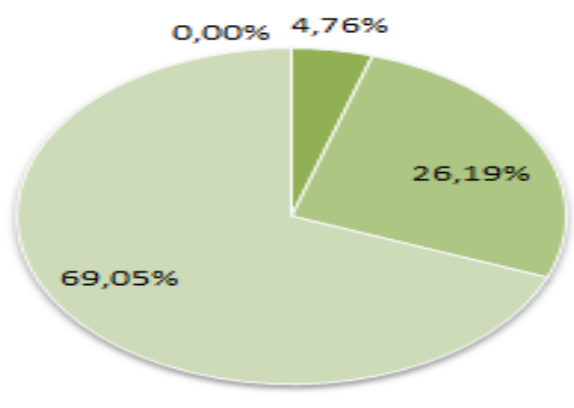

- Não influenciou
= Influenciou pouco
= Influenciou
$=$ Influenciou muito

Fonte: Autor (2020). 
Figura 6 - Resultados referentes à influência do Curso para elaboração de materiais didáticos dos monitores.

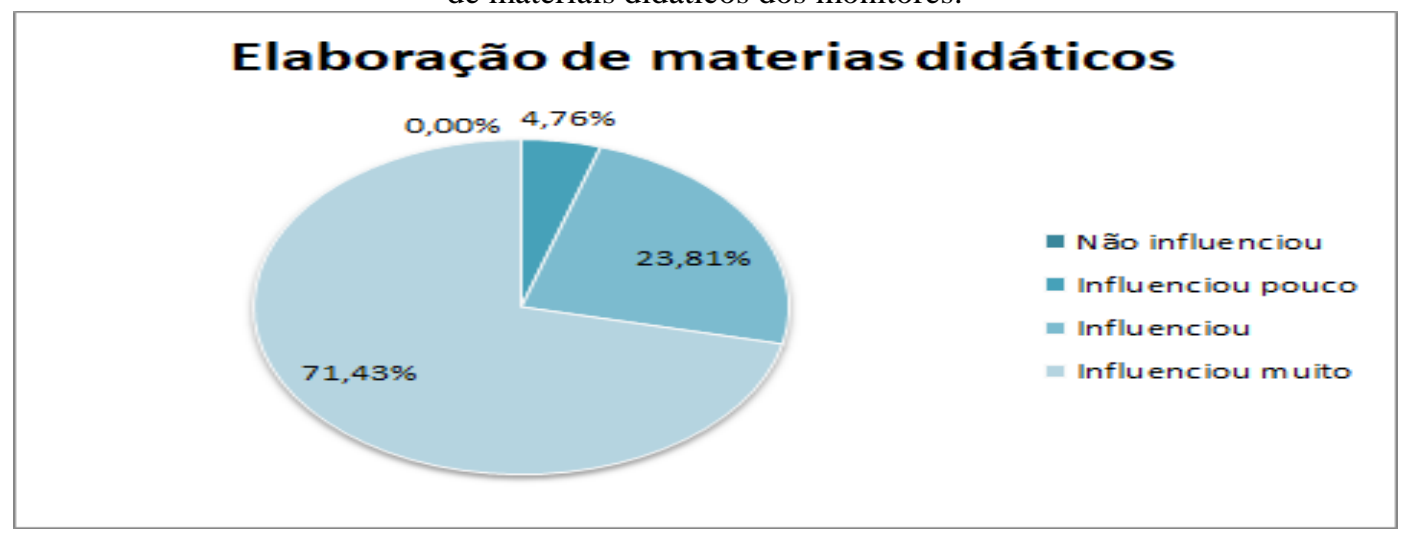

Fonte: Autor (2020).

Na Figura 4, onde é questionada a influência do Curso no desenvolvimento ou aprimoramento para a oratória do monitor, observou-se que 64,29\% afirmaram que influenciou muito; 33,33\% afirmaram que influenciou; 2,38\% afirmaram que influenciou pouco; 0,00\% afirmou que não influenciou. Na Figura 5, mostra que 69,05\% dos monitores optaram por "Influenciou muito" como melhor opção para mensurar o desenvolvimento ou aprimoramento da organização didática dos mesmos. 26,19\% escolheram "Influenciou"; $4,76 \%$ optaram por "Influenciou pouco"; $0,00 \%$ por "Não influenciou". Na figura 6 , item que questiona o quanto o Curso auxiliou no desenvolvimento ou aprimoramento para elaboração de materiais didáticos, notou-se que $71,43 \%$ afirmaram que influenciou muito; 23,81\% afirmaram que influenciou; $4,76 \%$ afirmaram que influenciou pouco; $0,00 \%$ afirmou que não houve influência. Os resultados supracitados só ratificam a importância do Curso de Matemática Básica para o desenvolvimento destes atributos para os monitores. Já que, nas três figuras - Figura 4, Figura 5, Figura 6 - a opção de "Influenciou muito" aparece com mais de $60 \%$. Principalmente para os que almejam seguir o percurso para se tornarem docentes, visto que, por se tratar de uma Universidade de engenharia, tais competências não estão presentes na grade curricular, como nos cursos de licenciatura.

As figuras a seguir - Figura 7, Figura 8 e Figura 9, respectivamente -, apresentam os resultados obtidos sobre o quanto o curso influenciou no desenvolvimento ou aprimoramento de características pessoais, que servem tanto para a área acadêmica, quanto para quaisquer profissões:

Figura 7 - Resultados referentes à influência do Curso no aprendizado nas disciplinas com alto grau de matematicidade.

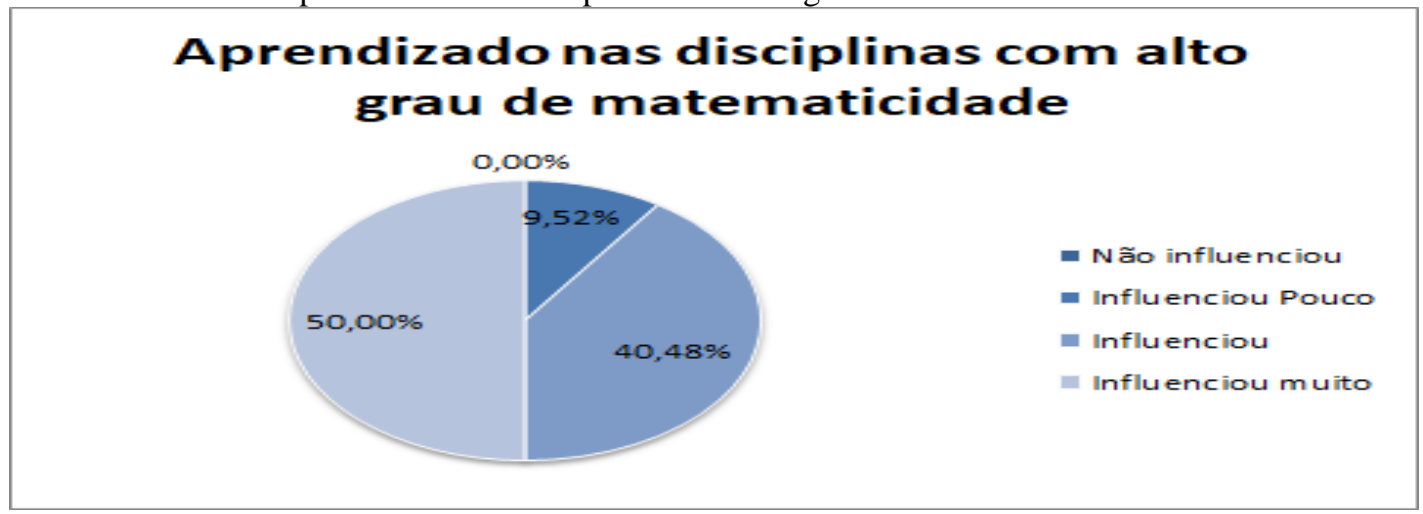

Fonte: Autor (2020). 
Figura 8 - Resultados referentes à influência Curso para a liderança.

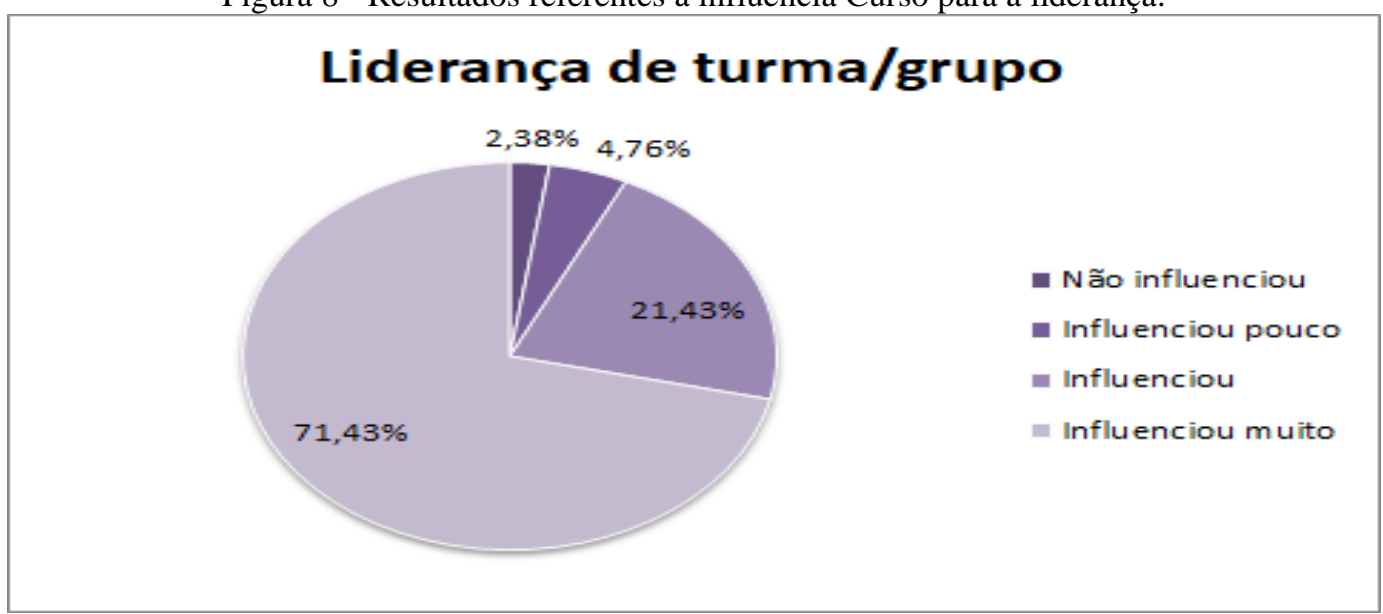

Fonte: Autor (2020).

Figura 9 - Resultados referentes à influência do Curso na graduação.

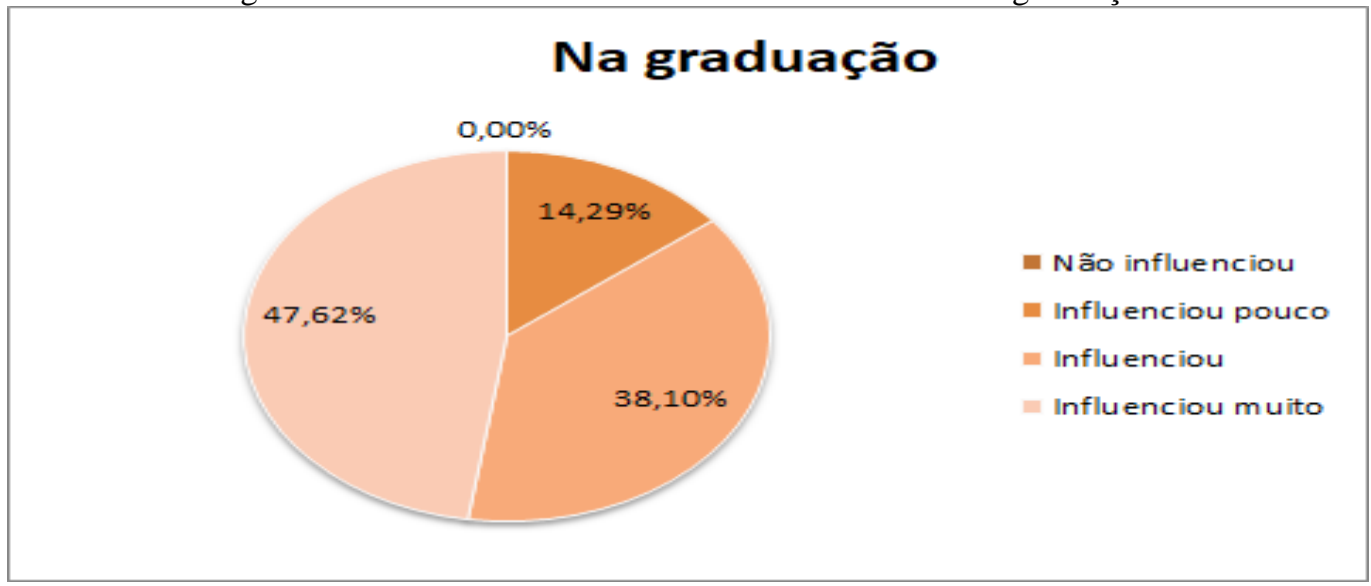

Fonte: Autor (2020).

Na Figura 7, onde é indagado o quanto o Curso influenciou no desenvolvimento ou aprimoramento em disciplinas com alto grau de matematicidade, foi visto que: 50,00\% afirmaram que influenciou muito; 40,48\% afirmaram que influenciou; 9,52\% afirmaram que influenciou pouco; $0,00 \%$ afirmou que não influenciou.

Na figura 8, onde foi abordado o quanto o Curso influenciou no desenvolvimento ou aprimoramento para liderança de turma/grupo, constatou-se que: $71,43 \%$ afirmaram que influenciou muito; $21,43 \%$ afirmaram que influenciou; $4,76 \%$ afirmaram que influenciou pouco; $2,38 \%$ afirmaram que não influenciou.

Na figura 9, onde foi questionado o quanto o Curso influenciou no desenvolvimento ou aprimoramento na graduação do monitor, reparou-se que: 47,62\% afirmaram que influenciou muito; $38,10 \%$ afirmaram que influenciou; $14,29 \%$ afirmaram que influenciou pouco; $0,00 \%$ afirmou que não influenciou.

Os resultados apresentados acima exibem que o Curso teve sua parcela de importância também nas disciplinas da graduação, especialmente para as que exigem um nível maior de matematicidade. Assim como, mais de $70 \%$ dos monitores confirmaram a relevância do papel de monitor para o desenvolvimento ou aprimoramento da liderança, característica tão importante para o mercado de trabalho. 


\section{CONSIDERAÇÕES FINAIS}

As práticas exercidas pelos monitores no Curso de Matemática Básica da POLI/UPE, tornam-se um formador de perfil docente em seus monitores, pois características intrínsecas à função são estimuladas em seu período de realização. Vale salientar o despertar vocacional a docência que pode ser adquirido pelo afeto do monitor com a função exercida.

A partir da avaliação realizada na pesquisa, aspectos importantes foram revelados: o projeto mostrou-se positivo, tanto para a otimização organizacional quanto intelectual, bem como também, o aprimoramento dos atributos inerentes à docência, o que denota a função de formador que o projeto agrega aos monitores. Em contrapartida, ainda que satisfatória, a influência no processo de graduação apresentou os menores resultados positivos, ressaltando que o Ensino Superior exige mais do que é absorvido no Curso.

Baseado nos resultados obtidos e com possíveis estudos futuros - voltados para pesquisas com docentes que colaboraram com o projeto - o Curso de Matemática Básica continua em seu processo de aprimoramento contínuo, visando à evolução da prática docente dos monitores e otimizando o aprendizado de seus alunos, auxiliando-os no início da graduação.

\section{Agradecimentos}

Agradecemos a todos os que já se envolveram e/ou estão envolvidos neste Projeto, principalmente aos monitores, que exercem sua função em sala e contribuíram para que esse estudo fosse realizado. Aos membros integrantes da coordenação do Curso, tanto os Docentes, quantos os Discentes. Aos coordenadores da POLI/UPE. A pedagoga do Núcleo de Apoio Psicopedagógico Inclusivo - NAPSI, Anna Lúcia e a toda sua equipe de estudantes veteranos, por todo o apoio. E, por fim, a equipe de Gestão da POLI/UPE. A todos estes, nossa gratidão.

\section{REFERÊNCIAS}

ALMEIDA, Eustáquio D.; GODOY, Elenilton V. A evasão nos cursos de engenharia: uma análise a partir do cobenge. In: XLIV Congresso Brasileiro de Educação em Engenharia, 2016, Rio Grande do Norte. Anais. Natal, 2016.

\section{ÁLVARES, Vanessa O. M. O docente-engenheiro frente aos desafios da formação pedagógica no Ensino Superior. Disponível em: https://repositorio.ufu.br/bitstream/123456789/13824/1/VOMAlvaresDISSPRT.pdf. Acesso em: 24 mar. 2020.}

COSTA, Jefferson S.; BALTAR, Solma L. S. M. D. A. A importância e concepção da monitoria de estágio supervisionado para alunos do curso de licenciatura em biologia. Disponível em: http://seer.uftm.edu.br/revistaeletronica/index.php/revistagedeles/article/view/811/1142. Acesso em: 24 mar. 2020.

FERRUZZI, E. C.; ALMEIDA, L. M. W. Modelagem matemática no ensino de matemática para engenharia. Revista Brasileira de Ensino de Ciência e Tecnologia, Paraná, v. 6, n. 1, jan/abr. 2013.

FREITAS, Bruno A.; COSTA, Érika C. A. C.; COSTA, Cláudio P. Fatores da evasão discente no curso de engenharia civil da Universidade Estadual da Paraíba. XLIV Congresso Brasileiro 
"Os desafios para formar hoje o engenheiro do amanhã"

de Educação em Engenharia, 2016, Rio Grande do Norte. Anais. Natal, 2016.

MIRANDA, Cleiton G. M.; LAUDARES, João B. A matemática na atuação profissional do engenheiro. In: XXXIX Congresso Brasileiro de Educação em Engenharia, 2011, Santa Catarina. Anais. Blumenau, 2011.

SANTOS, Daniel F. D.; BOSCAINO, Eloiza G.; PAVÃO, Augusto C. Avaliação da contribuição da monitoria para o desempenho do aluno de engenharia - um estudo de caso na Escola de Engenharia Mauá. XXXIV Congresso Brasileiro de Educação em Engenharia, 2006, Rio Grande do Sul. Anais. Passo Fundo, 2006.

SANTOS, Daone da Silva et al. Curso introdutório de matemática para engenharia (CIME): contribuições para um melhor desempenho nas disciplinas iniciais. XL Congresso Brasileiro de Educação em Engenharia, 2012, Pará. Anais. Belém, 2012.

\title{
THE INFLUENCE OF THE BASIC MATHEMATICS COURSE OF THE POLYTECHNIC SCHOOL OF THE UNIVERSITY OF PERNAMBUCO ON ITS MONITORS
}

\begin{abstract}
The Escola Politécnica de Pernambuco decided to create the Basic Mathematics Course for the incoming students, with the purpose of leveling and preparing them for their new realities. This course, taught by veteran students, with the thought of: who could be better for this preparation than people who have been through the same situation? Focusing on these monitors, this article aims to show a research conducted with them, in which is possible to quantify the influence on the development or improvement of personal and academic characteristics inherent to teaching and other professions. The study was developed using Google Forms' platform, consisting of a questionnaire divided into two stages: the first one consisting of a collection of informations related to the academic profile, and the second one, focusing on relevant aspects in the formation of a teaching profile. The contact, obtained through a database, was made via e-mail and instant messaging application, the most effective method of collection. As a result, we highlight: in the first stage, 10 of the 17 undergraduate monitors entered the Master's degree, continuing their academic trajectory. And, in the second, $71.43 \%$ of the interviewees affirmed a strong influence in the development of teaching materials and group or class leadership, showing the influence that the project has on their monitor. From this, it is possible to confirm the formative and influential characters of the project in the development of such attributes, and with this, the importance of research in showing the merit of the Course for part of its students.
\end{abstract}

Keywords: Teaching. Influence. Basic Mathematics. Monitor. 